Original Article

\title{
Relationship between advanced glycation end-product accumulation in the skin and pulmonary function
}

\author{
Akira Kubo, MD, PhD ${ }^{1,2)}$, Michitaka Kato, PhD ${ }^{2 *}$, Yosuke Sugioka ${ }^{3)}$, Rie Mitsui ${ }^{3)}$, \\ Nobuki Fukuhara ${ }^{3)}$, Fumi Nihei, $\mathrm{MS}^{1)}$, Yoshiniko Takeda, MD, $\mathrm{PhD}^{4)}$ \\ 1) Anti-Aging Center, Ginza Hospital, Japan \\ 2) Department of Shizuoka Physical Therapy, Faculty of Health Science, Tokoha University: \\ 1-30 Mizuochi-cho, Aoi-ku, Shizuoka 420-0831, Japan \\ 3) Department of Clinical Laboratory, Ginza Hospital, Japan \\ 4) Department of Internal Medicine, Ginza Hospital, Japan
}

\begin{abstract}
Purpose] This study aimed to evaluate the relationship between advanced glycation end-product accumulation and pulmonary function in a general population with normal spirometry results. [Subjects and Methods] A total of 201 subjects (mean age, $56 \pm 11$ years; males, $58 \%$ ) enrolled in this study. Subjects were classified into two groups (younger group [ $<65$ years old] and elderly group [ $\geq 65$ years old]). Skin autofluorescence was assessed as an estimate of advanced glycation end-product. Forced vital capacity and forced expiratory volume in one second were measured using a spirometer, and the forced expiratory volume in one second/forced vital capacity ratio (FEV1/ FVC) was calculated. [Results] Skin autofluorescence was not an independent factor associated with FEV1/FVC in the younger group, but both skin autofluorescence and pack-years of smoking were significant independent factors associated with FEV1/FVC in the elderly group. [Conclusion] Advanced glycation end-product accumulation, assessed by skin autofluorescence, is an independent factor negatively associated with FEV1/FVC in elderly people with normal spirometry results.

Key words: Advanced glycation end product, FEV1/FVC, Elderly
\end{abstract}

(This article was submitted Nov. 17, 2017, and was accepted Dec. 12, 2017)

\section{INTRODUCTION}

Chronic obstructive pulmonary disease (COPD) remains a major public health problem and is projected to rank fifth in global disease burden by $2020^{1}$. COPD is induced by long-term cigarette smoking, and is primarily characterized by the presence of airflow limitations resulting from airway inflammation and remodeling and the development of emphysema ${ }^{2)}$. Chronic inflammation occurs not only in the airways of COPD patients, but throughout the body as well, given that inflammatory mediators are known to spread from the lung to the rest of the body ${ }^{2)}$.

According to recent studies, the level of advanced glycation end products (AGEs) increases with age and is higher in smokers and COPD patients ${ }^{3,4)}$. AGEs are bioactive molecules formed by the nonenzymatic glycation or peroxidation of proteins, lipids, and nucleic acids ${ }^{5,6}$. AGEs increase inflammation by binding to receptors for AGE (RAGE), which are present on cell surfaces in tissues ${ }^{5,7}$. Therefore, AGE accumulation may play a role in the pathogenesis of COPD by increasing inflammation ${ }^{8)}$.

Several AGEs, such as pentosidine and Ne-(Carboxymethyl)-L-lysine (CML), have been reported to emit a characteristic fluorescence in human skin ${ }^{9}$. AGEs assessed by skin autofluorescence (SAF) could help in the rapid evaluation of AGE

*Corresponding author. Michitaka Kato (E-mail: katomanzooo@gmail.com)

C) 2018 The Society of Physical Therapy Science. Published by IPEC Inc.

This is an open-access article distributed under the terms of the Creative Commons Attribution Non-Commercial No Derivatives (by-nc-nd) License. (CC-BY-NC-ND 4.0: https://creativecommons.org/licenses/by-nc-nd/4.0/) 
accumulation in clinical settings ${ }^{9}$. Recently, SAF was reported to be higher in COPD patients compared with healthy con$\operatorname{trols}^{3,10)}$. However, it is unclear whether SAF is related to pulmonary function in subjects with normal spirometry results.

Investigating factors associated with deteriorations in pulmonary function could help develop strategies to prevent the development of COPD in people with normal spirometry results, particularly given the serious impact of COPD on the risk of chronic disabilities and mortality. Therefore, we focused on the relationship between AGEs and pulmonary function in a general population with normal spirometry results. Moreover, given that aging is accompanied by an increase in AGEs and a decrease in pulmonary function ${ }^{4}, 11$ ), it would be informative to compare relationships between AGEs and pulmonary function in younger and elderly individuals. To this end, the present study aimed to evaluate the relationship between SAF and pulmonary function in younger and elderly people with normal spirometry results.

\section{SUBJECTS AND METHODS}

This cross-sectional study was performed with approval form the Ethics Committee of Ginza Hospital (approval number: 27-1). All subjects were informed about the study and provided written consent.

Two hundred and seventy-two males and females who underwent a medical checkup at Ginza Hospital were enrolled in this study. Subjects underwent hematological examinations and additional assessments, such as the accumulation of AGEs in skin and pulmonary function.

Between June 2014 and March 2016, 272 subjects had participated in the Anti-Aging Dock. Of these, 269 (151 males) participated in our study and provided informed consent for data analysis (response rate, 98.8\%). Subjects with an obstructive, restrictive, or mixed disorder pattern on the pulmonary function test were excluded. In addition, subjects with diseases that could influence pulmonary function (e.g., COPD, interstitial pneumonia, or asthma) or who received medications that could influence pulmonary function were excluded. Those with diabetes or hemoglobin A1c $(\mathrm{HbA} 1 \mathrm{c})>6.5 \%$ were also excluded since diabetes and glycemic levels are known to be associated with both pulmonary function and level of SAF ${ }^{12,13)}$. The final study population consisted of 201 subjects (116 males).

Pulmonary function is known to decrease with age, with marked reductions occurring after the age of $65^{11,14)}$. Moreover, older people (65 years and above) were reported to have risk factors for COPD ${ }^{15)}$. Therefore, subjects were classified into two groups with a cut-off value of 65 years old: those aged $<65$ years (younger group; 145) and those aged $>65$ years (elderly group; 56).

Measurements of AGEs, pulmonary function, and blood parameters were conducted in the morning. We instructed subjects to avoid taking any medication, drinking coffee or alcohol and eating for at least eight hours prior to the measurement. Subjects were also requested to refrain from exercise of moderate to vigorous intensity before measurements.

SAF was assessed using an AGE Reader (DiagnOptics Technologies B.V., Groningen, The Netherlands) and used as a surrogate for $\mathrm{AGEs}^{16)}$. SAF is known to reflect the amount of AGE accumulation in skin and interrelate with pentosidine levels in skin biopsies, serum pentosidine, or CML levels ${ }^{3,9)}$. It has been reported that SAF obtained from AGE Reader showed high validity and reliability. Stirban A et al. reported that SAF measurements have an intra-subject variability of below $11 \%$ in patients with type 2 diabetes ${ }^{17}$. Furthermore, SAF is significantly associated with cardiovascular events and mortality in patients with cardiovascular disease ${ }^{18}$.

Forced vital capacity (FVC), forced expiratory volume in one second (FEV1), and percent predicted FEV1 (\%FEV1) were measured using a spirometer (SP370 Hyper, FUKUDA DENSHI, Tokyo, Japan) according to the guidelines of the Japanese Respiratory Society (JRS $)^{19)}$. The higher value from twice FVC measurements was recorded as the analytical value. Data were expressed as a ratio or as a percentage of predicted values (FEV1/FVC and \%FVC).

Blood pressure was measured with an automatic sphygmomanometer (HBP-9021, OMRON COLIN, Tokyo, Japan) following a 3-minute rest. White blood cell (WBC) counts were measured using the hematology analysis method (HORIBA Ltd., Kyoto, Japan). HbA1c levels were assessed with the latex agglutination method (Kyowa Medex, Tokyo, Japan). Serum high-density lipoprotein cholesterol (HDL-C) and low-density lipoprotein cholesterol (LDL-C) concentrations were assessed with the direct assay method (Sekisui Medical, Tokyo, Japan) ${ }^{20)}$. Plasma triglycerides (TG) were assayed using routine enzymatic methods (Kyowa Medex, Tokyo, Japan) ${ }^{20)}$. Serum creatinine $(\mathrm{Cr}$ ) was assessed with the enzyme assay method (Nittobo Medical, Tokyo, Japan $)^{20)}$. Estimated glomerular filtration rate (eGFR) was calculated using the following formula, which is specific to the Japanese population: eGFR $\left(\mathrm{ml} / \mathrm{min} / 1.73 \mathrm{~m}^{2}\right)=194 \times$ Serum creatinine $^{-1.094} \times$ Age $^{-0.287} \times 0.739$ (if female $)^{21)}$.

Subject characteristics including age, gender, smoking status (non, former, or current smoker), pack-years of smoking, alcohol-drinking status (non, 1-6 days/week, or 7 days/week), comorbidities (hypertension [HT] and dyslipidemia [DL]), and medication use were obtained from medical records.

Levels of physical activity were measured by the International Physical Activity Questionnaire (IPAQ) short version ${ }^{22)}$. Physical activity levels of subjects were divided into three categories (low, moderate, or high) according to IPAQ's original $\operatorname{algorithm~}^{20)}$.

Data were expressed as mean \pm standard deviation (SD) and percentages. Statistical significance was analyzed by comparing variables between the two groups using the unpaired Student's t-test or Fisher's exact test.

Relationships between FEV1/FVC and variables, or SAF and variables were assessed using Spearman's rank correlation coefficient. Multiple linear regression analysis using the backward-selection method was performed with age, gender, BMI, 
Table 1. Subject characteristics

\begin{tabular}{|c|c|c|c|}
\hline & Total & Younger group & Elderly group \\
\hline Number of subjects & 201 & 145 & 56 \\
\hline Age (years) & $56 \pm 11$ & $51 \pm 8$ & $69 \pm 7^{* *}$ \\
\hline Male/Female & $116 / 85$ & $89 / 56$ & $27 / 29$ \\
\hline BMI $\left(\mathrm{kg} / \mathrm{m}^{2}\right)$ & $23.0 \pm 3.3$ & $22.9 \pm 3.2$ & $23.1 \pm 3.5$ \\
\hline HDL-C (mg/dl) & $60 \pm 16$ & $61 \pm 17$ & $59 \pm 14$ \\
\hline LDL-C (mg/dl) & $126 \pm 32$ & $126 \pm 32$ & $129 \pm 35$ \\
\hline $\mathrm{TG}(\mathrm{mg} / \mathrm{dl})$ & $103 \pm 64$ & $101 \pm 72$ & $109 \pm 35$ \\
\hline eGFR $\left(\mathrm{ml} / \mathrm{min} / 1.73 \mathrm{~m}^{2}\right)$ & $83.1 \pm 16.1$ & $84.7 \pm 15.8$ & $74.8 \pm 15.1^{* *}$ \\
\hline HbAlc (\%) & $5.5 \pm 0.3$ & $5.4 \pm 0.3$ & $5.6 \pm 0.3$ \\
\hline $\operatorname{WBC}\left(10^{3} / \mu \mathrm{l}\right)$ & $6188 \pm 1823$ & $6280 \pm 1861$ & $5712 \pm 1552$ \\
\hline SBP (mmHg) & $122 \pm 15$ & $120 \pm 14$ & $135 \pm 17^{* *}$ \\
\hline HT $(\%)$ & 14 & 8 & $30^{* *}$ \\
\hline DL $(\%)$ & 7 & 6 & 10 \\
\hline Antihypertensive drug (\%) & 16 & 9 & $36^{* *}$ \\
\hline Lipid-lowering drug (\%) & 5 & 4 & 9 \\
\hline Other drugs $(\%)$ & 19 & 18 & 24 \\
\hline Physical activity level (low/moderate/high PA) (\%) & $80 / 15 / 5$ & $87 / 9 / 4$ & $45 / 45 / 10^{* *}$ \\
\hline Drinking status (non/1-6 days/week/7 days/week) (\%) & $30 / 39 / 31$ & $27 / 38 / 35$ & $41 / 41 / 18$ \\
\hline Smoking status (non/former/current smoker) (\%) & $48 / 21 / 31$ & $46 / 19 / 35$ & $58 / 27 / 15$ \\
\hline Pack-years of smoking & $16.5 \pm 10.6$ & $13.0 \pm 8.6$ & $25.7 \pm 9.6^{* *}$ \\
\hline$\% \mathrm{FVC}(\%)$ & $98.7 \pm 11.3$ & $99.2 \pm 11.4$ & $97.4 \pm 10.9$ \\
\hline FEV1/FVC & $0.83 \pm 0.07$ & $0.84 \pm 0.07$ & $0.80 \pm 0.06^{*}$ \\
\hline$\%$ FEV1 (\%) & $0.93 \pm 0.15$ & $0.94 \pm 0.16$ & $0.91 \pm 0.12$ \\
\hline SAF (AU) & $1.9 \pm 0.4$ & $1.8 \pm 0.3$ & $2.1 \pm 0.4^{* *}$ \\
\hline
\end{tabular}

Data are expressed as mean \pm standard deviation (SD) for continuous variables, and as number of subjects (\%) for categorical variables. AU: arbitrary units; BMI: body mass index; DL: dyslipidemia; eGFR: estimated glomerular filtration rate; FEV1: force expiratory volume in one second; FVC: forced vital capacity; HbAlc: hemoglobin A1c; HDL-C: highdensity lipoprotein cholesterol; HT: hypertension; LDL-C: low-density lipoprotein cholesterol; PA: physical activity; SAF: skin autofluorescence; TG: triglyceride; SBP: systolic blood pressure; WBC: white blood cell; \%FEV1: percent predicted force expiratory volume in one second. ${ }^{*} \mathrm{p}<0.05,{ }^{* *} \mathrm{p}<0.01$ (vs. Younger group).

TG, WBC, pack-years of smoking, and SAF as exploratory variables, and FEV1/FVC as the dependent variable. The selection of exploratory variables was carried out by considering previous studies and relationships between FEV1/FVC and other variables $^{10,23)}$. Categorical variables used in multiple linear regression analyses were set as female (0) or male (1) for gender, and non smoker $(0)$ or former and current smoker (1) for smoking status.

$\mathrm{P}<0.05$ was considered statistically significant. All analyses were performed using SPSS 19.0 for Windows (SPSS Statistics, IBM, Tokyo, Japan).

\section{RESULTS}

Subject characteristics are shown in Table 1. A total of 116 male and 85 female subjects participated in this study. Table 1 also summarizes the characteristics by group. The younger and elderly groups had 145 (mean age, $51 \pm 8$ years) and 56 (mean age, $69 \pm 7$ years) subjects, respectively. Age, systolic blood pressure (SBP), HT prevalence, use of antihypertensive drugs, physical activity level, pack-years of smoking, and SAF were significantly higher in the elderly group compared to the younger group $(\mathrm{p}<0.001, \mathrm{p}<0.001, \mathrm{p}=0.003, \mathrm{p}<0.001, \mathrm{p}<0.001, \mathrm{p}<0.001$, and $\mathrm{p}<0.001$, respectively). FEV1/FVC and eGFR were significantly lower in the elderly group compared to the younger group $(\mathrm{p}=0.047$ and $\mathrm{p}=0.002$, respectively). There were no significant differences in gender ratio, BMI, HDL-C, LDL-C, TG, HbA1c, WBC, DL, lipid-lowering and other drugs, drinking status, smoking status, $\% \mathrm{FVC}$, and \%FEV1 between the two groups.

Relationships between FEV1/FVC and variables are shown in Table 2. FEV1/FVC was significantly correlated with age, HDL-C, eGFR, and WBC in the younger group $(r=-0.223, p=0.005 ; r=0.172, p=0.040 ; r=0.166, p=0.047 ; r=-0.170, p=0.037$, respectively). On the other hand, FEF1/FVC was significantly correlated with gender, LDL-C, pack-years of smoking, and SAF in the elderly group $(r=0.369, p=0.034 ; r=0.384, p=0.044 ; r=-0.548, p=0.034 ; r=-0.446, p=0.002$, respectively).

Association between SAF and variables are shown in Table 3. SAF was significantly correlated with age, gender, BMI, 
Table 2. Relationships between FEV1/FVC and variables in younger and elderly groups

\begin{tabular}{lccc}
\hline & Younger group & & Elderly group \\
\cline { 2 - 3 } & $\mathrm{r}$ & $\mathrm{r}$ \\
\hline Age & $-0.223^{* *}$ & & -0.139 \\
Gender (male) & 0.102 & & $0.369^{*}$ \\
BMI & -0.135 & & 0.052 \\
HDL-C & $0.172^{*}$ & & 0.069 \\
LDL-C & -0.021 & & $0.384^{*}$ \\
TG & -0.103 & & 0.107 \\
eGFR & $0.166^{*}$ & & 0.258 \\
HbAlc & -0.147 & & -0.027 \\
WBC & $-0.170^{*}$ & & 0.007 \\
SBP & 0.026 & & 0.231 \\
Antihypertensive drug & -0.048 & -0.025 \\
Lipid-lowering drug & 0.126 & 0.289 \\
Pack-years of smoking & 0.037 & $-0.548^{*}$ \\
SAF & -0.025 & $-0.446^{* *}$ \\
\hline
\end{tabular}

FEV1: force expiratory volume in one second; FVC: forced vital capacity; BMI: body mass index; HDL-C: high-density lipoprotein cholesterol; LDL-C: low-density lipoprotein cholesterol; TG: triglyceride; eGFR: estimated glomerular filtration rate; HbAlc: hemoglobin A1c; WBC: white blood cell; SBP: systolic blood pressure; SAF: skin autofluorescence. ${ }^{*} \mathrm{p}<0.05$, $* * \mathrm{p}<0.01$.
Table 3. Relationships between SAF and variables in younger and elderly groups

\begin{tabular}{lccc}
\hline & Younger group & Elderly group \\
\cline { 2 - 2 } Age & $\mathrm{r}$ & $\mathrm{r}$ \\
\hline Gender (male) & $0.417^{* *}$ & & -0.326 \\
BMI & $-0.293^{* *}$ & & -0.234 \\
HDL-C & $-0.265^{* *}$ & & 0.191 \\
LDL-C & 0.005 & & -0.120 \\
TG & $0.217^{* *}$ & -0.025 \\
eGFR & -0.118 & -0.143 \\
HbAlc & -0.035 & -0.221 \\
WBC & 0.082 & 0.085 \\
SBP & 0.068 & 0.021 \\
Antihypertensive drug & -0.091 & 0.011 \\
Lipid-lowering drug & 0.044 & -0.032 \\
Pack-years of smoking & 0.001 & -0.222 \\
\%FVC & 0.173 & $-0.581^{*}$ \\
\%FEV1 & 0.021 & 0.306 \\
\hline
\end{tabular}

BMI: body mass index; HDL-C: high-density lipoprotein cholesterol; LDL-C: low-density lipoprotein cholesterol; TG: triglyceride; eGFR: estimated glomerular filtration rate; HbAlc: hemoglobin A1c; WBC: white blood cell; SBP: systolic blood pressure; \%FVC: percent forced vital capacity; \% FEV1: percent force expiratory volume in one second. ${ }^{*} \mathrm{p}<0.05,{ }^{* *} \mathrm{p}<0.01$.

and LDL-C in the younger group $(r=0.417, p<0.001 ; r=-0.293, p<0.001 ; r=-0.265, p<0.001 ; r=-0.217$, $p=0.009$, respectively). On the other hand, SAF was significantly correlated only with pack-years of smoking in the elderly group $(\mathrm{r}=-0.581$, $\mathrm{p}=0.023$ ).

Table 4 shows the results of multiple linear regression analyses in the younger and elderly groups. Although SAF was not an independent factor negatively associated with FEV1/FVC in the younger group, SAF and pack-years of smoking were significant independent factors associated with FEV1/FVC in the elderly group $(\beta=-5.862, p=0.009,95 \% \mathrm{CI}-10.132$ to $-1.592 ; \beta=-0.203, p=0.002,95 \% \mathrm{CI}-0.324$ to -0.082 , respectively).

\section{DISCUSSION}

This study aimed to evaluate the relationship between SAF and FEV1/FVC in two different age groups of people with normal spirometry results. We found that SAF is an independent factor negatively associated with FEV1/FVC in elderly people with normal spirometry results, but not in younger people.

Pack-years of smoking was a significant independent factor associated with FEV1/FVC in the elderly group. Cigarette smoke contains many reactive oxygen species (ROS) and free radicals that elevate oxidative stress ${ }^{24}$. A previous animal study reported that elevated oxidative stress led to goblet cell hyperplasia of the airway epithelium and mucus hypersecretion, resulting in increased airway limitations ${ }^{25)}$. In addition, ROS in cigarette smoke could increase levels of inflammatory cytokines such as tumor necrosis factor $\alpha(\mathrm{TNF}-\alpha)$ or interleukin 6 (IL-6) through nuclear factor kappa B NF- $\kappa \mathrm{B}$, a master regulator of pro-inflammatory genes ${ }^{7,26)}$. Previous studies have also shown that inflammatory cytokines promote neutrophil migration and macrophage infiltration into the airway epithelium ${ }^{27)}$. These infiltrating macrophages and migrating neutrophils release matrix metallopeptidase 12 (MMP-12) and neutrophil elastase, leading to the breakdown of alveolar walls ${ }^{28,29)}$. Findings among the elderly group in the present study are in line with many previous reports indicating that smoking is associated with decreased FEV1/FVC.

This study demonstrated that SAF is an independent factor associated with FEV1/FVC in the elderly group. According to other studies, AGEs in the blood and AGE accumulation in skin were higher in smokers than in non-smokers ${ }^{3,4)}$. It is possible that smoking induced AGE accumulation among our subjects because we excluded patients with diabetes or hyperglycemia who are likely to have increased AGEs. AGEs can bind to and activate RAGE, which are present on cell surfaces in tissues, especially in the lung ${ }^{5)}$. Activation of RAGE increases inflammation via NF- $\kappa B^{7)}$. Therefore, the decrease in FEV1/FVC was likely accelerated by AGE accumulation.

With respect to the younger group, SAF was not associated with decreased FEV1/FVC. There are several potential ex- 
Table 4. Multiple linear regression analyses using FEV1/FVC as a dependent variable in younger and elderly groups

\begin{tabular}{|c|c|c|c|c|c|c|}
\hline & \multicolumn{3}{|c|}{ Younger group } & \multicolumn{3}{|c|}{ Elderly group } \\
\hline & $\beta$ & $\mathrm{p}$ & $95 \% \mathrm{CI}$ & $\beta$ & $\mathrm{p}$ & $95 \% \mathrm{CI}$ \\
\hline Age (1 year increase) & -0.103 & 0.147 & -0.243 to 0.037 & 0.119 & 0.373 & -0.152 to 0.390 \\
\hline Gender (male) & 2.263 & 0.028 & 0.255 to 4.272 & -0.027 & 0.992 & -5.313 to 5.259 \\
\hline BMI ( $1 \mathrm{~kg} / \mathrm{m}^{2}$ increase $)$ & -0.006 & 0.972 & -0.322 to 0.311 & -0.138 & 0.657 & -0.778 to 0.502 \\
\hline TG (1 mg/dl increase) & -0.028 & $<0.001$ & -0.042 to -0.014 & 0.040 & 0.064 & -0.003 to 0.082 \\
\hline WBC (1/ $\mu 1$ increase) & 0.001 & 0.001 & 0.001 to 0.002 & 0.001 & 0.409 & -0.001 to 0.002 \\
\hline Smoking (1 pack-year increase) & -0.049 & 0.381 & -0.158 to 0.061 & -0.203 & 0.002 & -0.324 to -0.082 \\
\hline \multirow[t]{3}{*}{ SAF (1 AU increase) } & 1.759 & 0.332 & -1.815 to 5.333 & -5.862 & 0.009 & -10.132 to -1.592 \\
\hline & $\mathrm{r}$ & 0.411 & & $\mathrm{r}$ & 0.683 & \\
\hline & $r^{2}$ & 0.169 & & $r^{2}$ & 0.466 & \\
\hline
\end{tabular}

FEV1: force expiratory volume in one second; FVC: forced vital capacity; BMI: body mass index; TG: triglyceride; WBC: white blood cell; SAF: skin autofluorescence; AU: arbitray units.

planations for the differences observed between the younger and elderly groups regarding factors associated with FEV1/ FVC. First, the value of SAF is strongly related to age ${ }^{30}$. In the present study, the value of SAF was significantly lower in the younger group compared to the elderly group. Therefore, inflammation resulting from AGEs might have been lower in younger subjects, resulting in the maintenance of FEV1/FVC. Second, the amount and/or activity of endogenous antioxidant enzymes between the two groups may have differed. It is well known that ROS can be buffered by endogenous antioxidant enzymes such as superoxide dismutase (SOD) and catalase ${ }^{31)}$, and previous studies have demonstrated that levels of these antioxidant enzymes decrease with age ${ }^{32}$. Therefore, younger subjects may have had higher levels of antioxidant enzymes, in addition to a lower level of oxidative stress, compared to the elderly, thereby resulting in a stable FEV1/FVC. Thus, pulmonary function could potentially be maintained by preventing AGE accumulation earlier in life.

The use of SAF to estimate FEV1/FVC could be beneficial in many clinical situations. A number of limitations and contraindications of the pulmonary function test are known, including unstable cardiovascular conditions (e.g., heart attack or stroke in the last 3 months, uncontrolled hypertension with systolic blood pressure $>200 \mathrm{mmHg}$, aortic aneurysm $)^{33)}$. Moreover, it is difficult to carry out the pulmonary function test in patients with dementia or impaired consciousness because the test requires the examinee's voluntary effort. This contrasts with the assessment of SAF, which does not require effort from the examinee. Thus, assessing SAF in combination with smoking status may provide a simple way to estimate FEV1/ FVC in patients whose lung function is difficult to test.

This study has some limitations worth noting. First, given the cross-sectional design of the study, we could not assess whether SAF directly affects pulmonary function. Second, although assessing parameters of oxidative stress, antioxidants, and inflammation is important for understanding the relationship between AGEs and decreased FEV1/FVC, we did not assess these parameters. Although we adjusted for confounding factors such as gender, comorbidities, and lifestyle, we did not exclude the possibility that pulmonary function was affected by other confounders such as air pollution or genetic disposition. Therefore, further prospective studies should be conducted to determine whether a causal relationship exists between decreased FEV1/FVC and SAF. Finally, our sample size of the elderly group was too small to allow sufficiently powered statistical analysis because we set the cut-off point of 65 years old based on the current literature.

In conclusion, AGE accumulation, assessed by SAF, is an independent factor negatively associated with FEV1/FVC in elderly people with normal spirometry results.

\section{Conflict of interest}

None.

\section{REFERENCES}

1) Rabe KF, Hurd S, Anzueto A, et al. Global Initiative for Chronic Obstructive Lung Disease: Global strategy for the diagnosis, management, and prevention of chronic obstructive pulmonary disease: GOLD executive summary. Am J Respir Crit Care Med, 2007, 176: 532-555. [Medline] [CrossRef]

2) Barnes PJ, Celli BR: Systemic manifestations and comorbidities of COPD. Eur Respir J, 2009, 33: 1165-1185. [Medline] [CrossRef]

3) Gopal P, Reynaert NL, Scheijen JL, et al.: Plasma advanced glycation end-products and skin autofluorescence are increased in COPD. Eur Respir J, 2014, 43: 430-438. [Medline] [CrossRef]

4) Yue X, Hu H, Koetsier M, et al.: Reference values for the Chinese population of skin autofluorescence as a marker of advanced glycation end products accumulated in tissue. Diabet Med, 2011, 28: 818-823. [Medline] [CrossRef]

5) Semba RD, Nicklett EJ, Ferrucci L: Does accumulation of advanced glycation end products contribute to the aging phenotype? J Gerontol A Biol Sci Med Sci, 
2010, 65: 963-975. [Medline] [CrossRef]

6) Fu MX, Requena JR, Jenkins AJ, et al.: The advanced glycation end product, Nepsilon-(carboxymethyl)lysine, is a product of both lipid peroxidation and glycoxidation reactions. J Biol Chem, 1996, 271: 9982-9986. [Medline] [CrossRef]

7) Luevano-Contreras C, Chapman-Novakofski K: Dietary advanced glycation end products and aging. Nutrients, 2010, 2: 1247-1265. [Medline] [CrossRef]

8) Wu L, Ma L, Nicholson LF, et al.: Advanced glycation end products and its receptor (RAGE) are increased in patients with COPD. Respir Med, 2011, 105: 329-336. [Medline] [CrossRef]

9) Meerwaldt R, Graaff R, Oomen PH, et al.: Simple non-invasive assessment of advanced glycation endproduct accumulation. Diabetologia, 2004, 47: 13241330. [Medline] [CrossRef]

10) Hoonhorst SJ, Lo Tam Loi AT, Hartman JE, et al.: Advanced glycation end products in the skin are enhanced in COPD. Metabolism, 2014, 63: 1149-1156. [Medline] [CrossRef]

11) Xu X, Laird N, Dockery DW, et al.: Age, period, and cohort effects on pulmonary function in a 24-year longitudinal study. Am J Epidemiol, 1995, 141: 554-566. [Medline] [CrossRef]

12) Davis WA, Knuiman M, Kendall P, et al. Fremantle Diabetes Study: Glycemic exposure is associated with reduced pulmonary function in type 2 diabetes: the Fremantle Diabetes Study. Diabetes Care, 2004, 27: 752-757. [Medline] [CrossRef]

13) Sugisawa E, Miura J, Iwamoto Y, et al.: Skin autofluorescence reflects integration of past long-term glycemic control in patients with type 1 diabetes. Diabetes Care, 2013, 36: 2339-2345. [Medline] [CrossRef]

14) Quanjer PH, Stanojevic S, Cole TJ, et al. ERS Global Lung Function Initiative: Multi-ethnic reference values for spirometry for the 3-95-yr age range: the global lung function 2012 equations. Eur Respir J, 2012, 40: 1324-1343. [Medline] [CrossRef]

15) Ding Y, Xu J, Yao J, et al.: The analyses of risk factors for COPD in the Li ethnic group in Hainan, People's Republic of China. Int J Chron Obstruct Pulmon Dis, 2015, 10: 2593-2600. [Medline] [CrossRef]

16) Gerrits EG, Lutgers HL, Kleefstra N, et al.: Skin autofluorescence: a tool to identify type 2 diabetic patients at risk for developing microvascular complications. Diabetes Care, 2008, 31: 517-521. [Medline] [CrossRef]

17) Stirban A, Pop A, Fischer A, et al.: Variability of skin autofluorescence measurement over 6 and 12 weeks and the influence of benfotiamine treatment. Diabetes Technol Ther, 2013, 15: 733-737. [Medline] [CrossRef]

18) de Vos LC, Mulder DJ, Smit AJ, et al.: Skin autofluorescence is associated with 5-year mortality and cardiovascular events in patients with peripheral artery disease. Arterioscler Thromb Vasc Biol, 2014, 34: 933-938. [Medline] [CrossRef]

19) [Guideline of respiratory function tests-spirometry, flow-volume curve, diffusion capacity of the lung]. Nihon Kokyuki Gakkai Zasshi, 2004 , Suppl: 1-56.

20) Kato M, Kubo A, Sugioka Y, et al.: Relationship between advanced glycation end-product accumulation and low skeletal muscle mass in Japanese men and women. Geriatr Gerontol Int, 2017, 17: 785-790. [Medline] [CrossRef]

21) Matsuo S, Imai E, Horio M, et al. Collaborators developing the Japanese equation for estimated GFR: Revised equations for estimated GFR from serum creatinine in Japan. Am J Kidney Dis, 2009, 53: 982-992. [Medline] [CrossRef]

22) Craig CL, Marshall AL, Sjöström M, et al.: International physical activity questionnaire: 12-country reliability and validity. Med Sci Sports Exerc, 2003, 35: 1381-1395. [Medline] [CrossRef]

23) Sato K, Shibata Y, Abe S, et al.: Association between plasma adiponectin levels and decline in forced expiratory volume in $1 \mathrm{~s}$ in a general Japanese population: the Takahata study. Int J Med Sci, 2014, 11: 758-764. [Medline] [CrossRef]

24) Chow CK: Cigarette smoking and oxidative damage in the lung. Ann N Y Acad Sci, 1993, 686: 289-298. [Medline] [CrossRef]

25) Takeyama K, Jung B, Shim JJ, et al.: Activation of epidermal growth factor receptors is responsible for mucin synthesis induced by cigarette smoke. Am J Physiol Lung Cell Mol Physiol, 2001, 280: L165-L172. [Medline]

26) Hasnis E, Bar-Shai M, Burbea Z, et al.: Cigarette smoke-induced NF-kappaB activation in human lymphocytes: the effect of low and high exposure to gas phase of cigarette smoke. J Physiol Pharmacol, 2007, 58: 263-274. [Medline]

27) Shoji S, Ertl RF, Koyama S, et al.: Cigarette smoke stimulates release of neutrophil chemotactic activity from cultured bovine bronchial epithelial cells. Clin Sci (Lond), 1995, 88: 337-344. [Medline] [CrossRef]

28) Hautamaki RD, Kobayashi DK, Senior RM, et al.: Requirement for macrophage elastase for cigarette smoke-induced emphysema in mice. Science, 1997, 277: 2002-2004. [Medline] [CrossRef]

29) Shapiro SD, Goldstein NM, Houghton AM, et al.: Neutrophil elastase contributes to cigarette smoke-induced emphysema in mice. Am J Pathol, 2003, 163: 2329-2335. [Medline] [CrossRef]

30) Koetsier M, Lutgers HL, de Jonge C, et al.: Reference values of skin autofluorescence. Diabetes Technol Ther, 2010, 12: 399-403. [Medline] [CrossRef]

31) Pandey KB, Rizvi SI: Markers of oxidative stress in erythrocytes and plasma during aging in humans. Oxid Med Cell Longev, 2010, 3: 2-12. [Medline] [CrossRef]

32) Niwa Y, Ishimoto K, Kanoh T: Induction of superoxide dismutase in leukocytes by paraquat: correlation with age and possible predictor of longevity. Blood, 1990, 76: 835-841. [Medline]

33) Cooper BG: An update on contraindications for lung function testing. Thorax, 2011, 66: 714-723. [Medline] [CrossRef] 